\title{
Future options to reduce RhD immunization in addition to a high coverage prevention program of antenatal and postnatal RhIg: a nationwide cohort study
}

\author{
Yolentha Slootweg ${ }^{1}$, Carolien Zwiers ${ }^{2}$, Johanna Koelewijn ${ }^{3}$, Ellen van der Schoot $^{3}$, Dick \\ Oepkes ${ }^{4}$, Inge Kamp ${ }^{2}$, and Masja de Haas ${ }^{5}$ \\ ${ }^{1}$ Leiden University Medical Center \\ ${ }^{2}$ Leiden Universitair Medisch Centrum \\ ${ }^{3}$ Sanquin Research \\ ${ }^{4}$ Leiden University Medical Centre \\ ${ }^{5}$ Sanquin Research Clinical Transfusion Research
}

July 21, 2021

\begin{abstract}
Objective: To evaluate which risk factors for $\mathrm{RhD}$ immunization remain, despite adequate routine antenatal and postnatal $\mathrm{RhIg}$ prophylaxis (1000 IU RhIg) and additional administration of RhIg. Assessment of the prevalence of RhD immunizations. Design: Prospective cohort Setting: The Netherlands. Population: Two-year nationwide cohort. Methods: RhD-negative women in their first RhD immunized pregnancy and their foregoing non-immunized pregnancy. Risk factors for RhD immunization were compared with population data. Main outcomes measures: Risk factors for FMH and subsequently RhD immunization, prevalence of RhD immunizations. Results: The prevalence of newly detected RhD immunizations was $0.31 \%$ (79/25,170) of all RhD-negative pregnant women in the Netherlands. After exclusion, 193 women remained. Significant risk factors found in the group of 113 parous women (previous pregnancy $>16$ weeks, RhD positive child) were; caesarean section (CS) (OR 1.7, 95\% CI 1.1-2.6), perinatal death (OR 3.5, 95\% CI 1.1-10.9), gestational age over 42 weeks (OR 6.1, 95\% CI 2.2-16.6), postnatal bleeding (>1000mL) (OR $2.095 \%$ CI 1.1-3.6), surgical removal of the placenta (SRP) (OR 4.3, 95\% CI 2.0-9.3). The miscarriage rate in the group of women without a previous RhD positive child was significantly higher than in the Dutch population (35\% vs $12.5 \% \mathrm{p}<0.001)$. Conclusion: Complicated deliveries, including cases of major bleeding and surgical interventions (CS, SRP) need to be recognized as risk factor, requiring determination of FMH volume and adjustment of RhIg dosing. Miscarriage may be an additional risk factor for RhD immunization, requiring further studies. Funding: This research was partly funded by a grant from Sanquin Amsterdam.
\end{abstract}

\section{Hosted file}

Future options to reduce RhD-immunization YM 08062021.docx available at https://authorea.com/ users/426888/articles/531239-future-options-to-reduce-rhd-immunization-in-addition-toa-high-coverage-prevention-program-of-antenatal-and-postnatal-rhig-a-nationwide-cohortstudy

\section{Hosted file}

Figure 1 Composition of the study population.docx available at https://authorea.com/users/ 426888/articles/531239-future-options-to-reduce-rhd-immunization-in-addition-to-a-highcoverage-prevention-program-of-antenatal-and-postnatal-rhig-a-nationwide-cohort-study 


\section{Hosted file}

Figure 2 Association of significant parturition-related risk factors.docx available at https: //authorea.com/users/426888/articles/531239-future-options-to-reduce-rhd-immunizationin-addition-to-a-high-coverage-prevention-program-of-antenatal-and-postnatal-rhig-anationwide-cohort-study 